\title{
El humor político como discurso para fomentar control democrático
}

\section{Political humor as a discourse that encourage democratic control \\ Humor político como discurso para promover o controle democrático}

\author{
Ana María Acosta Marín ${ }^{1}$ \\ Universidad Andina Simón Bolívar (Ecuador) \\ ana.acosta.m@gmail.com
}

Fecha de recepción: 31 de enero de 2019

Fecha de recepción evaluador: 19 de marzo de 2019

Fecha de recepción corrección: 07 de abril de 2019

\begin{abstract}
Resumen
¿Es el humor político un discurso que fomenta el control democrático de la gestión pública a través de la discusión y opinión?, para responder a la premisa se desarrolló un análisis de dos videos de humor publicados en YouTube que dan cuenta de la realidad política de Colombia desde un tono satírico y humorístico: "Fuimos a marchar contra la corrupción (pero no les gustó) FT Vladdo" del canal YouTube Hola Soy Danny del periodista Daniel Samper Ospina, y “¿Por qué nadie se mete con Álvaro Uribe?” del canal de opinión La Pulla en YouTube, del periódico El Espectador, videos que fueron

\footnotetext{
${ }^{1}$ Ana María Acosta es Licenciada en Comunicación social y periodismo por la Universidad Externado de Colombia, Especializada en Comunicación Social por la Universidad Andina Simón Bolívar. Su labor profesional se ha desarrollado en la consultoría de comunicaciones estratégicas para organismos internacionales y entidades no gubernamentales. Ha desarrollado su actividad investigadora en análisis del discurso. En la actualidad desarrolla estrategias de comunicación para proyectos y organismos no gubernamentales. https://orcid.org/0000-0002-9850-1238
} 
analizados bajo la propuesta de Teun van Dijk para desentramar las representaciones mentales de la ideología que comparte una sociedad democrática, desde la estructura del discurso. El resultado de la investigación demostró que a través del humor político como estrategia discursiva es posible desentramar los discursos que vulneran la ideología compartida por una sociedad democrática, no solo porque al disgregar el pensamiento en unidades comprensibles (a través del humor) se señala a quienes transgreden las normas impuestas, sino también porque genera el debate, necesario para el control democrático.

Palabras clave: Humor político, sarcasmo, sátira, democracia, ideología, discurso.

\begin{abstract}
Is political humor a discourse that encourage democratic oversight of public management through discussion and opinion? To respond to the premise, an analysis of two humor videos published on YouTube was worked out, that show the political reality of Colombia from a satirical and humorous tone: "We went to march against corruption (but they didn't like it) FT Vladdo" from YouTube channel of journalist Daniel Samper Ospina: Hola Soy Danny and "Why doesn't anyone pick on Álvaro Uribe?" from newspaper El Espectador YouTube opinion channel La Pulla, videos that were analyzed under the proposal of Teun van Dijk to unveil ideology mental representations shared by a democratic society, from the discourse structure. The result of the investigation showed that through political humor as a discursive strategy it is possible to unveil the discourses that infringes shared ideology by a democratic society, not only because by disaggregating thinking into comprehensible units (through humor) it is possible to pointed out to those who transgress the imposed norms, but also because it generates debate, necessary for democratic control.
\end{abstract}

Keywords: Political humor, sarcasm, satire, democracy, ideology, discourse

\title{
Resumo
}

Humor político é um discurso que promove o controle democrático da gestão pública através da discussão e opinião?, para responder a análise premissa de dois vídeos engraçados postados no YouTube perceber a realidade política de desenvolvimento Colômbia, de um tom satírico e bem-humorado: "Fomos marchar contra a corrupção (mas eles não gostaram) FT Vladdo" do canal do YouTube Olá, sou Danny do jornalista Daniel Samper Ospina e "Por que ninguém mexe com Álvaro Uribe?" Do canal de opinião La Pulla no YouTube, do jornal El Espectador, Vídeos que foram analisados sob a proposta de Teun van Dijk para desvendar as representações mentais da ideologia que uma sociedade democrática compartilha, desde a estrutura do discurso. O resultado da investigação mostrou que, através do humor político como estratégia discursiva, é possível desvendar discursos que violam a ideologia compartilhada por uma sociedade democrática, não só porque, ao fragmentar o pensamento em unidades compreensíveis (através do humor), é apontado para aqueles que transgridem as normas impostas, mas também porque gera o debate necessário para o controle democrático. 
Palavras-chave: Humor político, sarcasmo, sátira, democracia, ideología, discurso.

\section{Introducción}

De acuerdo con lineamientos del marco jurídico del Sistema Interamericano de Protección de los Derechos Humanos, para que una democracia funcione correctamente necesita un mayor nivel de discusión pública sobre todos los asuntos de la sociedad y el Estado, en todos sus aspectos, no solo porque fomenta la transparencia y la responsabilidad de los funcionarios públicos, también porque permite la participación ciudadana. Esto implica la aceptación de la circulación de opiniones e ideas, que podrían pasar por la crítica humorística como forma de opinión. Desde esta perspectiva, este ensayo busca responder a la interrogante: ¿es el humor político un discurso que fomenta el control democrático de la gestión pública a través de la discusión y opinión?

Bajo este cuestionamiento se pretende analizar el poder del discurso en el humor político como ejercicio pedagógico de discusión pública para el mejor funcionamiento de la democracia, que exige, tanto para los funcionarios públicos como para los asuntos de interés público, un mayor nivel de escrutinio y circulación de opiniones e ideas para el ejercicio de un sistema verdaderamente democrático.

Para apoyar la premisa se analizará el discurso de dos programas online de crítica política en Colombia: "Fuimos a marchar contra la corrupción (pero no les gustó) FT Vladdo" del canal YouTube Hola Soy Danny del periodista Daniel Samper Ospina, y “¿Por qué nadie se mete con Álvaro Uribe?” del canal de opinión La Pulla en YouTube, del periódico El Espectador, en los cuales se critican posturas ideológicas y comentarios del expresidente colombiano Álvaro Uribe Vélez.

Ambos programas colombianos analizan semanalmente, a través de la sátira y el sarcasmo, sucesos coyunturales del devenir en la política colombiana, por lo tanto las situaciones referidas, los personajes analizados y el lenguaje empleado responden al universo de representaciones simbólicas e históricas propias de Colombia.

\section{Marco referencial}

Una primera referencia que busca abarcar este ensayo, previo a la revisión de posturas referentes al análisis del discurso, es el alcance del derecho a la libertad de expresión que aborda el marco jurídico del sistema interamericano de protección de los derechos humanos, esto con el único fin de cotejar los hallazgos de los casos analizados para este ensayo y dar paso a la respuesta de la premisa planteada.

Este alcance al derecho de la libertad de expresión, que se aborda desde el marco jurídico del sistema interamericano (la Convención Americana, la Declaración Americana y la Carta Democrática Interamericana), es condición indispensable para la consolidación, el funcionamiento, y la preservación de los regímenes democráticos, y en ese orden de ideas prevenir sistemas autoritarios, facilitar a la autodeterminación personal y colectiva y hacer operativos de control y denuncia ciudadana. (CIDH, 2010, p. 3). 
Por lo tanto, salvaguardar un derecho específico de expresión que permita el funcionamiento de sistemas democráticos, implica abarcar la expresión humana en toda su dimensión a la vez que se faculta la posibilidad de buscar, recibir y difundir información y opinión libremente "por cualquier medio de comunicación” (CIDH, 2010, p. 7).

En virtud del derecho de la difusión de información y opinión, la Corte Interamericana de Derechos Humanos garantiza las difusión de ideas favorables, pero también las que pueden ofender, inquietar o perturben al Estado en pro del pluralismo, la tolerancia y el espíritu de apertura, categorías primordiales para la existencia de una sociedad democrática (CIDH, 2010, p. 10), que necesita a su vez un mayor nivel de discusión pública sobre el funcionamiento de la sociedad, y específicamente sobre asuntos de interés público.

El control democrático de la gestión pública, a través de la opinión pública, fomenta la transparencia de las actividades del Estado y la responsabilidad de los funcionarios públicos sobre sus actuaciones, y es un medio para lograr el máximo nivel de participación ciudadana. De allí que el adecuado desenvolvimiento de la democracia requiera la mayor circulación de informes, opiniones e ideas sobre asuntos de interés público. (CIDH, 2010, p. 11)

Estas opiniones e ideas pueden venir de la mano del humor político (caricatura, crítica, ironía, sátira, sarcasmo), porque su intención comunicativa se presenta como instrumento de denuncia y crítica social.

Para el lingüista T. Van Dijk, estas opiniones, o puntos de vista, que presuponen un juicio basado en valores y normas que son socialmente compartidos, es decir que están representadas por proposiciones que caracterizan predicados evaluativos, es esto, predicados que presuponen valores (van Dijk, Ideologías, 1999, p. 55), se inscriben en un sistema de creencias sociales. Tal sistema de creencias, por pertenecer a un ámbito de lo social, implica que es compartido entre sus miembros "nuestro casto conocimiento del mundo está constituido por tales creencias social y culturalmente compartidas" (van Dijk, Ideologías, 1999, p. 48).

A estas creencias sociales (opiniones, criterios de verdad, valores) se inscriben las representaciones mentales es decir aquellas ideas, comportamientos y sistemas de valores que, para poder orientar, buscan definir un orden en el grupo y como fin secundario asegurar la comunicación entre sus miembros, proporcionando:

"criterios de pertenencia y acceso al grupo (¿Quiénes somos nosotros?, ¿Quién pertenece a nuestro grupo?), acciones típicas y objetivos (¿Qué hacemos y por qué?), normas y valores (¿Qué es bueno y qué es malo para nosotros?), la posición social en relación con otros grupos (¿Dónde estamos nosotros?), así como los recursos sociales especiales del grupo (¿Qué tenemos?)” (van Dijk, 2000, p. 52).

Así mismo, las representaciones mentales conforman sistemas básicos de la cognición social (conocimiento y actitudes compartidas de un grupo) y su sistema básico son las ideologías, "esencialmente sociales" (van Dijk, 1999, p. 49) por lo tanto, "las ideologías son las representaciones mentales que forman la base de la cognición social, 
esto es, del conocimiento y actitudes compartidos de un grupo" (van Dijk, 2000, p. 56), y le dirá a este cómo responder o cómo representarse, porque la ideología se desarrolla para coordinar lo que socialmente será compartido y la forma en que se manejará un conflicto.

Consecuentemente, la ideología como base del conocimiento precisa de la práctica del discurso para que la ideología se reproduzca, en donde esta a su vez controlará y moldeará al discurso "el significado o el contenido del discurso es controlado por las interpretaciones subjetivas por parte de los usuarios del idioma de la situación o eventos de los que trata el discurso, esto es, por sus modelos mentales" (van Dijk, 2005).

Por lo tanto, dado el rol de la ideología en las representaciones mentales de un colectivo, esta refleja cómo el grupo aborda o ve un acontecimiento determinado y además controla las opiniones sobre tales acontecimientos además del conocimiento (a través del discurso). Sin embargo el contenido del discurso es controlado por los modelos mentales, y por lo tanto subjetivo, de quien emplea el lenguaje. (van Dijk, 2005).

Es así que la ideología dictará para el colectivo qué es bueno o malo, correcto o incorrecto, lo que debe o no debe ser hecho, incitando para ello opiniones "puesto que las ideologías son sociales y están compartidas, ellas incluyen las opiniones sociales de un grupo" (van Dijk, 1999, p. 53) además que presuponen un "juicio basado en valores y normas socialmente compartidos" (van Dijk, 1999, p. 54).

Este control subjetivo (prejuiciado) da paso a discursos ideológicos que hablan desde un punto de vista negativo o positivo en vista del "prejuicio ideológico del modelo mental" (van Dijk, 2005), concordante con las opiniones, o en el caso de este ensayo, con el humor político como espacio valorativo de opinión o de resistencia contra una acontecimiento específico.

En este punto de inflexión, van Dijk se pregunta sobre la clase de creencias sociales que están involucradas en la ideología y cómo están organizadas. Si la práctica para que se reproduzca la ideología se da a través del discurso, este se desarrolla a través del lenguaje y la comunicación para que pueda explicitarse. Consecuentemente, es el conocimiento de la estructura del discurso el que puede develar la ideología subyacente.

Van Dijk propone un estudio de esta estructura a través de modelos fonológicos, gráficas sintácticas, léxicas, estilísticas, retóricas, proposiciones, coherencia, entre otras, para develar la ideología, además de un análisis semántico de los significados en el discurso, "metafóricamente hablando, entonces, las ideologías son 'gramáticas' de las prácticas sociales específicas de un grupo" (van Dijk, 2000, p. 52).

En consecuencia, y para dar soporte a la propuesta de T. van Dijk en cuanto al análisis semántico de los significados, este ensayo se valió de las propuestas de George Lakoff y Mark Johnson, quienes conciben a la metáfora como concepto que rige el pensamiento "nuestro sistema conceptual ordinario... es fundamentalmente de naturaleza metafórica” (Lakoff \& Johnson, 2004, p. 39). 
Gracias a las posturas de Lakoff y Johnson en las palabras es posible encontrar conceptos que estructuran lo que percibimos y cómo nos relacionamos, a través de las cuales el lenguaje evidencia el sistema conceptual que usualmente empleamos al pensar y actuar. Por lo que se afirma que el sistema conceptual humano es en gran medida metafórico.

El análisis, a través de las metáforas, se da en apoyo a un discurso cuyo lenguaje es el humor, y por lo tanto su forma discursiva tanto en el habla como en la imagen es una continua significación semántica, porque en vista de que su función es hacer crítica necesita plantear representaciones opuestas a las expresadas en el discurso político oficial.

Por otro lado, este ensayo retomó parte de las estructuras discursivas de análisis de videos, de acuerdo a la propuesta de Jesús González Requena y Amaya Ortiz, que encuentran en la metáfora delirante el objeto del deseo imaginario, con el objetivo de identificar en el discurso una temática de la seducción, en donde el Yo del sujeto en la identificación imaginaria es capturado.

Finalmente, para especificar el discurso al que se alude, se tomó como punto de partida el espacio valorativo de una ideología (que es social), en donde las opiniones vertidas por sus miembros pueden responder a discursividades distintas (para que la ideología se reproduzca).

Para este caso particular de análisis se seleccionó al humor como ese espacio valorativo de la ideología, en donde el humor responde tanto como estrategia discursiva como transgresora de un poder, que comporta "dos puntos de vista uno implícito (serio) y otro absurdo (ridículo). El primero contiene la fuerza ilocutiva, es decir, lo que se quiere movilizar en favor de la protesta; el segundo contiene la idea que se ataca, idea que manifiesta el tono burlesco y el punto de vista absurdo puesto en el interlocutor" (Heredia, 2013, p. 91).

\section{Metodología}

Para el presente análisis se tomaron como referencia dos canales de YouTube que dan cuenta de la realidad política de Colombia desde un tono satírico y humorístico, que buscan ilustrar y responder a la premisa planteada, y permiten por lo tanto comparar el tipo de lenguaje y la intencionalidad.

Los canales referidos conllevan un trasfondo político per se en vista del tipo de análisis que realizan, esto para comprender la fuente de la que se nutren sus comentarios o el objetivo que persiguen. Dani "el Samper Ospina es un reconocido periodista y escritor, perteneciente a una familia de tradición política y periodística en Colombia. Por otro lado, La Pulla es una columna de opinión del diario El Espectador, un periódico colombiano de corte editorial liberal que se autoproclama como propositivo y no de oposición. 
El primer video, de 12 minutos de duración, pertenece al canal de YouTube Hola soy Danny del periodista Daniel Samper Ospina, publicado el 1 de abril del 2017, en donde analiza, desde el humor político, la invitación a una marcha contra la corrupción convocada por el expresidente de Colombia desde el periodo 2002 - 2010 Álvaro Uribe Vélez, en medio de un debate por temas de corrupción durante su gobierno. El segundo video: La Pulla, un espacio de opinión en YouTube del periódico El Espectador (de 6 minutos de duración publicado el 1 de marzo del 2018), busca responder a la incomprensible aceptación del expresidente colombiano Álvaro Uribe Vélez, un personaje de la política colombiana inmerso en escándalos de corrupción.

Se realizó un análisis cualitativo de los discursos empleados en cada video a partir de los planteamientos metodológicos de Teunvan Dijk, no para verlos como discursos desde el poder sino como discursos que desde la opinión y la crítica pueden hace para conocer la macroestructura, microestructura y superestructura del discurso, además de aportes de Goerge Lakoff, Jesús González Requena y Amaya Ortiz, para clarificar conceptos propios del lenguaje político colombiano, y característicos del lenguaje de Daniel Samper, y dar cuenta de las propuestas que su discurso aportan al debate de los asuntos de interés público como ejercicio de un sistema democrático.

Por lo tanto para evidenciar el aporte que desde el humor y la sátira realizan ambos videos al ejercicio del escrutinio político, se seleccionaron como indicadores: las proposiciones, macroproposiciones y macrorreglas como arquitectura textual de la macroestructura de los discursos.

Posteriormente, para análisis de la microestructura del discurso, se revisaron las proposiciones textuales, roles semánticos, presentación de ideas y secuencias de la oración, como indicadores de la semántica oracional empleada, esto para comprender a semántica léxica del ejercicio. Asimismo, se revisaron las estrategias cognitivas y de enunciación desarrolladas.

Finalmente se analizó la estructura esquemática y retórica, como indicadores de la superestructura del discurso, así como las imágenes más relevantes que apoyaron la estructura del discurso.

En esta propuesta de estructura que incluye una revisión de expresiones fonéticas interesaron igualmente los modos de la paraverbalidad (entonación, ritmo) y los modos no verbales (gestos, lenguaje corporal) como significantes concomitantes de la estructura gramatical del discurso. 


\section{Hallazgos}

\section{Fuimos a marchar contra la corrupción (pero no les gustó)}

El programa "Fuimos a marchar contra la corrupción pero no les gusto (ft) Vladdo" documentó la intención del periodista Daniel Samper, junto al caricaturista Vladdo, de acceder a la marcha contra la corrupción convocada por el Procurador de la Nación Alejandro Ordóñez Maldonado y el expresidente Álvaro Uribe Vélez, pero llevando sus propias propuestas respecto a lo que consideraban como corrupción en Colombia.

Para comenzar a identificar la configuración discursiva del video, que se enmarca en una enunciación de tipo opinión argumentativa, porque busca hacer comprender su discurso (González \& Ortiz, 1999, p. 22), se identifica en primera instancia con una narratividad interpretada por el Yo, representando en quien comenta el relato: Daniel un periodista, que desde la sátira, evidencia situaciones de la política colombiana, exponiendo sus tesis desde el espacio de trabajo de su casa; Tú, visto en quien ve el video y lo comprende porque entiende el devenir social y político de Colombia y porque Daniel busca convencer con su opinión argumentada otra forma de ver la realidad, y en esta relación Yo - Tú interviene el Él/Ella, representada por el argumento: La Corrupción, aquella a quien se debe atacar.

Con el 'Ella', la Corrupción, avanzamos hacia el espacio especular, ese que hace ver, que obliga a detener la mirada, y con esta introducción se detiene la mirada en dos personajes: Álvaro Uribe y Alejandro Ordóñez, dos personalidades políticas que estuvieron (y están) bajo vigilancia por actos de corrupción. Con ellos el análisis discursivo se encuentra la metáfora delirante: Daniel denuncia que son Ellos quienes tienen la falsa verdad, Ellos son el "objeto del deseo" (González \& Ortiz, 1999, pág. 27), porque ellos son metáfora pura en su lucha contra la corrupción, pero también son metáfora del cinismo, en el concepto simbólico que propone Daniel, que al mismo tiempo él expone y acusa.

Asimismo, desde un análisis ideológico, se reconoce la necesidad de Daniel de exponer las falencias y errores cometidos por dos ideólogos conservadores de la derecha, que acuden a una exhibición pública de opinión en contra del mal uso de poder político en Colombia: una marcha contra la corrupción que Daniel busca evidenciar, en clara ironía, una 'marcha de corruptos contra la corrupción', pero que él mismo como ciudadano, en contra de la corrupción, busca acceder, no sólo para evidenciar el hecho también en el ejercicio de su derecho democrático. Esta ironía, como estrategia discursiva, "funciona como contraverdad, pues lo dicho explícitamente se desmiente por una información situacional o contextual explícita..." (Acosta \& Sánchez, 2004, p. 62).

Por otro lado, comprender las implicaciones que conlleva el ejercicio crítico y pedagógico desde el humor que profesa Daniel en su video con el fin de realizar control de la gestión pública, pasa por realizar un análisis crítico del discurso. 
Las proposiciones del discurso, como pilares de la macroestructura del video de Daniel Samper, señalan: 'Daniel encuentra el canal de un youtuber mayor de 40 años, un personaje polémico que destituyeron porque se demostró compra de su reelección / este personaje quemaba libros y promovió el empleo en Colombia, nombrando a familiares / Le agrada que Ordoñez sea youtuber para que no robe protagonismos a Popeye, otro 'youtuber del Uribismo' / Ordoñez, Popeye (criado por Pablo Escobar) y Uribe, promueven una marcha contra la corrupción / Todos tienen una historia de corrupción / $\mathrm{Si}$ estos personajes convocan a una marcha sobre la corrupción seguro es para promoverla, porque su corrupción es decente / Pero invitaban contra la corrupción en general / Por eso se Daniel se suma contra la corrupción / Invita al caricaturista Vladdo quien le ayuda a hacer los carteles porque los del presidente Santos costaron 400.000 / En la marcha contra la corrupción, los 'uribistas' le gritan 'enmermelados' y los sacan por traidores / Pero advierten que marcharán contra la corrupción de un solo lado / Y para pasar por corruptos cometerán actos de corrupción.

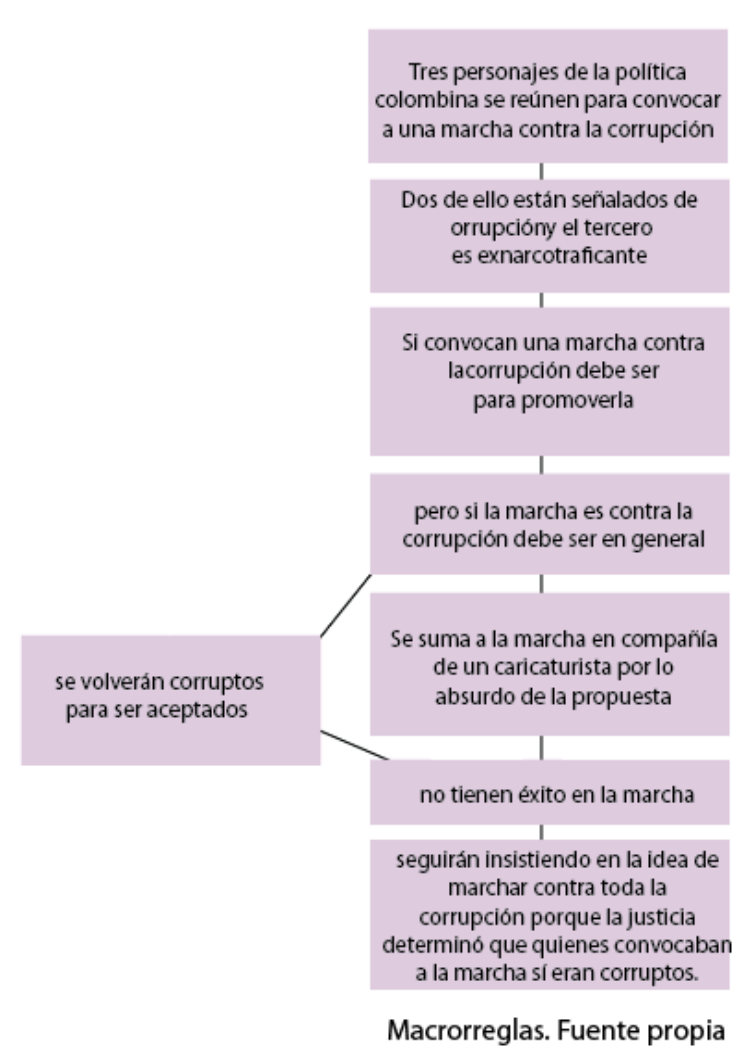

la marcha sí eran corruptos.

Respecto a la microestructura del discurso en Daniel Samper, se encontraron como proposiciones textuales: "al final de este capítulo estaré en una marcha" = ejerceré mi derecho ciudadano a reclamar / "invierto horas valiosas en aprender de mis colegas, es todo un viaje del intelecto" / como significado oculto a la pobre oferta analítica que circula en internet.

En su 'inversión' para el aprendizaje, Daniel se encuentra con una invitación de Alejandro Ordóñez (el exprocurador de Colombia) a una marcha contra la corrupción 
seguido de una cortinilla con las barras de color que siguen al corte de una transmisión de televisión con el característico tono de $1 \mathrm{kHz}$ para calibración de audio, es decir, al presenciar una situación paradójica (porque quien invita a la marcha contra la corrupción está inmerso en demandas por corrupción) le sigue la cortinilla, por lo tanto 'cortinilla de barra de colores' = me quedo sin palabras por lo ilógico de la situación, o 'sin palabras'. Asimismo, recuerda que Ordóñez además de haber sido destituido, quemaba libros en su juventud "El Goebbels búcaro fundador del Ku, Klux, Klan, capítulo Jirón” = el ideólogo bumangués (búcaro o de Bucaramanga) de propaganda del Tercer Reich, en este caso de Uribe, fundador de la organización de extrema derecha Ku Klux Kan versión colombiana, quien "ayudó a promover el empleo en Colombia, al menos de los familiares de los magistrados que debían elegirlo a él" cuando se mofa "Yo me nombro, tú te nombras, yo nombro a los tuyos, tú me nombras a mí, yo nombro a tu esposa y tú después me reeliges a mí" (Samper, 2017) = favoreció el nepotismo para que le devolviesen favores políticos, en evidente contexto de corrupción.

Al enlistar los nombres que acompañarán la marcha, cita a Popeye: "un hombre criado por su patrón Pablo Escobar" = una persona con los mismo criterios éticos de un narcotraficante; Álvaro Uribe "El Chaparrón Bonaparte del Dr. Ordóñez" = el dueto de bobos que, en un sinsentido, protestan, y quien además es "aquel personaje político, prócer de la moral, que solicitaba a sus congresistas que votaran antes de que fuesen enjuiciados" = Uribe, un político sin escrúpulos ni ética que pide a quienes van a ir a la cárcel por corrupción que voten por sus propuestas, en referencia al insólito requerimiento que hizo en el 2007 a los senadores en el Congreso de la República para que aprobaran proyectos de su gobierno cuando algunos de los senadores eran investigados por vínculos con el paramilitarismo en lo que se conoció como la parapolítica.

En clara alusión a Uribe, Daniel se muestra sobre un caballo de madera, tomando café y luciendo un sombrero aguadeño o sombrero paisa, proclama un discurso con acento típico de la región cafetalera de Colombia: "Hijitos, quiero pedir a todos los congresistas, que mientras no estén presos, salgan a marchar contra la corrupción" = Uribe, un político poseedor de vastas tierras que da discursos sobre su caballo (pero el caballo de un niño a quien no se le debe hacer caso porque juega con las palabras), haciendo solicitudes insólitas a congresistas, que están con procesos pendientes por corrupción.

En referencia al collar de arepas que recibiera en una condecoración simbólica, Daniel señala que las investigaciones de corrupción del caso Odebrecht en el gobierno de Uribe no prosperaron porque "alimentó su acuciosa mirada con carbohidratos y grasas, porque era de vista gorda" = Ordóñez es un político que no hiló fino en su investigación dejando pasar muchas pruebas que podrían incriminar a Uribe; y enfatiza que además debían haber puesto a su collar, chicharrones "porque tuvo muchos chicharrones por discriminar a las minorías" = mientras fue Procurador de la nación se le conoce por la cantidad de problemas que originaron sus comentarios hacia las comunidades LGTB, indígenas y matrimonio del mismo sexo. 
Daniel deduce consecuentemente que en vista de que la marcha fue convocada por Uribe y Ordóñez, esta debe ser para promoverla, en donde "quizá la única corrupción decente era la de ellos" = ellos sí pueden reunirse en evidente asocio de corrupción, por el caso Odebrecht, y hay impunidad, por eso la marcha debe ser para promover la corrupción, pero concluye que la marcha debería ser contra la corrupción, porque le "repugna la corrupción llena de mermelada de este gobierno, y más ahora que estoy a dieta" = no tolera el uso de dineros del Estado para beneficios privados o particulares cuando 'unta' a quienes quiere beneficiar"; no come ni "arepas ni mermelada" = no estoy de acuerdo ni con Ordõnez ni con la corrupción; y decide por lo tanto "protestar contra toda la corrupción" = no solo protesta desde el uribismo.

Al invitar al caricatura colombiano Vladdo para pintar los carteles de la marcha especifica que "son los carteles de la marcha, no los carteles de Medellín" = No los sicarios comandados por Pablo Escobar en la época del narcotráfico porque eso es tema de Popeye, el lugarteniente de Escobar, y así como especifica que son ellos quienes los pintarán, indica que "íbamos a comprar afiches, pero los afiches están muy caros, a Santos le costaron 400.000 USD" = nosotros no somos corruptos como el gobierno de Santos a quien el grupo Odebrecht le habría entregado 400.000 para su campaña en el 2010, como supuesta inversión para carteles.

Vladdo, se declara como experto en Uribe además de leer un libro ficticio sobre sus memorias, un libro hueco que contiene varios sistemas de almacenamiento informático externo (memorias y discos magnéticos) con información sobre procesos judiciales relacionado con Uribe, entre ellos: las interceptaciones telefónicas ilegales realizadas por el Departamento Administrativo de Seguridad (DAS) a líderes de oposición durante el mandato de Uribe; la vinculación de su hermano Santiago Uribe con bandas paramilitares llamadas 'Los 12 Apóstoles'; las visitas a la cárcel que realizó Uribe a César Villegas, alias 'El Bandi', una persona relacionada y condenada por el proceso 8.000 (un proceso judicial relacionado con financiamiento de dineros del narcotráfico a políticos colombianos). "lo sigo, lo leo, es un inspirador" / Uribe es material para mis caricaturas, por la gran cantidad de noticias sobre corrupción de las que es partícipe.

Vladdo comienza su caricatura con la propuesta de Daniel: Agro Ingreso Seguro (AIS) para que no se repita en la marcha con la corrupción, a lo que Vladdo responde "por eso un antioqueño ilustre como Andrés Felipe Arias, que ha hecho tanto contra la corrupción de este país", y de acuerdo con Daniel "asignó unos subsidios agrarios a terratenientes desamparados a los que nadie ayudaba" = El ministro, en flagrante uso de corrupción, que benefició con grandes sumas de dinero a políticos y terratenientes a través de un subsidio dirigido a campesinos. En un siguiente cartel "no más cohechos de una sola persona" Daniel comenta al respecto: "fue un hecho de corrupción que se dio en el gobierno de Álvaro Uribe, muy innovadora, porque consistió en un cohecho, de un soborno, que participó comprobadamente una persona pero no la otra" = Según Uribe el cohecho en su gobierno es de una sola persona y no como lo dictamina la ley, en referencia a actos de corrupción que permitieron cambios en la Constitución para la 
reelección de la presidencia de Uribe, en el cual una sola persona fue juzgada (caso 'Yidispolítica').

Antes de participar en la marcha una corte señala: "8.000 segundos después" (Samper, 2017), en referencia al 'proceso 8.000' (un proceso judicial efectuado durante la presidencia de Ernesto Samper, tío de Daniel Samper, bajo la acusación de recibir financiamiento del narcotráfico para su campaña) $=$ me pronuncio contra todo tipo de corrupción inclusive la que sucedió en mi familia. Al ingresar a la marcha, Daniel y Vladdo proclaman: "Corrupciones peye, marchemos con Popeye" = A pesar de que la corrupción es desagradable, marchamos junto a Popeye quien convocó contra la corrupción; "Ordóñez es un macho, yo soy un buen muchacho" = resulta valiente Ordóñez después de acusaciones probadas de corrupción, que además quiera realizar una protesta contra la corrupción; “¡Corrupción sí, pero no así!”= Esta falsa movilización contra la corrupción tiene evidentes tintes políticos, "Zona franca de occidente, presente, presente, presente" = aquí estamos quienes no aprobamos las zonas libres de impuestos después de ser adquiridas mediante acciones fraudulentas como la de los hijos de Uribe.

Al finalizar el video y después de ser amedrentados por la marcha uribista, Daniel se queja de que "no lograron obtener ni siquiera un lote en zona franca" = quienes marchaban desconocen, aprueban o demeritan el que los hijos de Uribe cometieran actos de corrupción; y advierte que comprará : "unas hectáreas a los Dávila Abondano, esconderemos nuestra declaración de rentas y seremos millonarios" = Para poder participar de esta insólita marcha me comportaré reprobatoriamente cometiendo actos de corrupción para ser aceptado por más gente que no comprende los niveles de corrupción del expresidente Uribe.

De acuerdo a los anteriores hallazgos se identifican los siguientes roles semánticos: Agente: Daniel Samper y Vladdo / Objeto: la corrupción / Instrumento: la marcha / Modo: la sátira política / Beneficiario: el pueblo colombiano / Causa: la exposición de la verdad frente a un hecho insólito / Oponente: Alejandro Ordóñez, Álvaro Uribe y los uribistas. Con este antecedente se puede estipular, en lo referente a la presentación de ideas, que Daniel presenta temas coyunturales de la política colombiana de forma no convencional, y resalta complejidades políticas desde la sátira para contrarrestar acciones que resultarían reiterativas de ser presentadas bajo una estructura de noticias formales, es decir, llama la atención porque juega con la semántica de las oraciones para construir sentido, sin embargo, desde una semántica léxica, las palabras que emplea son de uso común para quien conoce sobre la realidad colombiana, con terminología propia del dominio político, con palabras coloquiales como 'mermelada'.

Por otro lado, es posible identificar dos silogismos al inicio del discurso de Daniel, que marcan el ritmo de su argumento, en el primero señala que si Alejandro Ordóñez convoca a una marcha al igual que Álvaro Uribe, y si ambos están inmersos en demandas por corrupción, entonces la convocatoria a la marcha es para promover la corrupción, y la segunda, busca encontrar un sentido al sinsentido de tal argumento, por lo tanto si tanto Ordóñez como Uribe convocan a una marcha contra la corrupción, y si ambos están 
inmersos en demandas por corrupción, lo más probable es que él, Daniel, participará porque la convocatoria debe ser contra todo el concepto que engloba corrupción.

Estos silogismos, como estrategias de enunciación, transparentan el juego de palabras: se presupone que dos políticos inmersos en actos de corrupción convocan una marcha pero debe ser para 'promover' la corrupción, esto implica un sinsentido que infiere el tener que buscar una salida lógica, por lo tanto una nueva implicación con sentido lógico de la convocatoria a la marcha vincula a una idea con sentido coherente: la convocatoria debe ser para marchar contra toda la corrupción.

Como estrategia cognitiva, se diferencia una exhortación específica como leitmotiv del discurso de Daniel: "¡vamos a protestar contra la corrupción, pero contra toda la corrupción!" esto con el objetivo de guiar el proceso analítico que propone Daniel para llegar a determinada conclusión en quien le ve y comprende, es decir, llegar a la conclusión de que la convocatoria en contra de la corrupción convocada por personajes políticos inmiscuidos en procesos de demandas por corrupción resulta un sinsentido, y esto se expone con claridad gracias al lenguaje satírico, concatenando ideas, para lograr la coherencia local del discurso, comprendiendo primero algunos sucesos de la política colombiana y algunas metáforas propias del lenguaje colombiano.

Pasando a la superestructura del discurso, encontramos que la gramática del relato en Daniel está conformada de la siguiente forma narrativa: Daniel como periodista informa sobre una situación que está por desarrollarse, una situación que carece de toda lógica por los antecedentes, pero que apelando a la razón podría otorgarle sentido, por ello decide que se sumará a tal situación, pero una vez que se suma se evidencia el sin sentido inicial. Esta narratividad esclarece el contexto que tal propuesta debería generar en quien le ve, es decir, Daniel se pregunta si ¿se justifica que dos políticos inmersos en corrupción marchen contra la corrupción?, o por el contrario ¿es claro el mensaje que Daniel quiere transmitir?

En esta misma dirección, la estructura retórica que cumple su discurso se dirige hacia la perlocución, porque busca provocar un efecto, es decir, busca llamar la atención de quien le ve, que piense las consecuencias de lo que se está gestando con la convocatoria a la marcha y que vea el despropósito o sinsentido de la acción. Emplea como estrategia retórica la presentación de una situación para familiarizar a quien le ve con la temática del problema, luego apela a la razón para demostrar un sinsentido empleando para ello el humor "Cuando Uribe y Ordóñez convocaron a una marcha sobre la corrupción, inicialmente pensé que era para promoverla", y vuelve a argumentar que tal sin sentido no tiene fundamento y que por lo tanto debe implicar otra situación, en esta ocasión más razonada: "en una segunda mirada comprendí que no, que invitaban a marchar contra la corrupción en general" para lo cual asiste a la marcha, en donde evidencia efectivamente el sinrazón de la convocatoria, cuando al protestar contra la corrupción es amenazado por los simpatizantes de quien convoca, evidenciando nuevamente que el fin no es el originalmente planteado, sino una marcha cuyo fin es político afín a Uribe. 
Es importante tomar en cuenta que Daniel valida su discurso en un medio de uso masivo a través de internet: YouTube, cuyo canal cuenta con más de 940 mil visualizaciones, más de 380 mil suscripciones al canal, más de 7 mil comentarios, y cuya plataforma además permite comunicar contenido a través de audio y video, en donde las imágenes conforman un espacio discursivo adicional y complementario.

En el video resaltan tres imágenes con la doble intención de parodiar para, por un lado, llamar la atención sobre un hecho y, por otro, denunciar (para incitar el debate) a través de la crítica. Una de estas imágenes responde a Daniel sentado sobre un pequeño caballo de madera, tomando café y luciendo un sombrero aguadeño mientras pronuncia con acento paisa: "Hijitos, quiero pedir a todos los congresistas que nos han apoyado, que mientras no estén presos, salgan a marchar contra la corrupción" (Samper, 2017), una hipérbole de Uribe que pronuncia un discurso sinsentido que cobra sentido a través de la sátira, haciéndolo más comprensible.

Una segunda imagen es el cartel: "no más compra de reelecciones" que diseña Vladdo, en donde se ve la caricatura de Álvaro Uribe siendo bendecido por un Alejandro Ordóñez con investiduras clericales. Se emplea la figura retórica de la sátira porque la intención es desacralizar el discurso sinsentido, para darle sentido, a través de la mofa. De esta manera es un discurso haciendo referencia a otro discurso (interdiscursivo) para comprender en términos más simples que una figura de Ordóñez, que juega el papel de orientador moral, da su visto bueno a una figura de Uribe que con las manos juntas y una aureola falsa (porque está amarrada), como un falso santo, recibe el beneplácito de su ideólogo, en donde adicionalmente cantan al unísono en un 'coro angelical': "No a la compra de votos".

Una tercera, y última imagen que resalta es Vladdo y Daniel luciendo símbolos, en explícita referencia a las imágenes que acompañan la convocatoria a la marcha: sombreros aguadeños (sombrero típico paisa que suele usar Uribe), zapatos crocs (zapatos que usa regularmente y que le acompañaron durante las entrevistas del proceso de paz mientras los lucía con saco y corbata), tirantas (accesorio que usa Ordóñez para vestir), collar de arepas (por la investidura simbólica como hijo adoptivo del departamento de Antioquia que recibiera a cambio de la investidura oficial que le fuese negada como hijo adoptivo en vista del nulo aporte al departamento), camándula (por la inclinación religiosa de Ordóñez y la reiteración de unir la política con la religión en una país laico), hoja de espinacas (en relación a la convocatoria de Jhon Jairo Velázquez alias 'Popeye', lugarteniente del narcotraficante Pablo Escobar) y un guante negro o la 'mano negra' (en referencia a un comentario del presidente Juan Manuel Santos sobre un símbolo de violencia impune). Nuevamente, los símbolos se presentan en un ambiente de crítica y denuncia, Daniel y Vladdo se invisten de símbolos que se relacionan con la marcha para llamar la atención sobre los hechos, y para expresar críticamente el sinsentido de lo que se manifiesta o lo que está detrás de la marcha (quienes convocan la marcha).

Daniel continuamente juega con la sátira que, como modelo discursivo ideológico, busca manifestar su poder persuasivo apelando a valores como el bien, la 
verdad y la justicia (Llera, 1998-1999, p. 14). Asimismo, su discurso funge como medio para organizar sus creencias sociales, acerca de lo bueno o lo malo, correcto o incorrecto y actuar en consecuencia (van Dijk, Ideologías, 1999, p. 21), y es a través de este discurso que busca encontrar sentido a la sociedad y regular las prácticas sociales (van Dijk, Ideologías, 1999, p. 22).

En este juego de satirizar mediante su discurso elige un estilo léxico a través de eufemismos muy propios del lenguaje político colombiano: cuando especifica la palabra 'mermelada' hace referencia al clientelismo y la corrupción, es decir, el uso de dineros del Estado para beneficios privados o particulares cuando 'unta' a quienes quiere beneficiar, por lo tanto mermelada = corrupción.

Del mismo modo, al referirse sobre la intervención de Ordóñez como Procurador de la nación, enfatiza que éste "alimentó su acuciosa mirada con carbohidratos y grasas porque era de vista gorda" (Samper, 2017), como metáfora de su negación a atender los casos de corrupción vinculados a Odebrecth durante el gobierno de Uribe, y "a su collar [de arepas] han debido ponerle chicharrones...por discriminar a las minorías" (Samper, 2017), como eufemismo de problemas difíciles de afrontar y resolver, es decir, su incapacidad propició problemas difíciles de resolver con las minorías. Por último la hipérbole 'corrupción decente' es una crítica a la hipocresía de quienes convocan a la marcha. Tales lexicalizaciones expresan indirectamente los valores implícitos incorporados en los significados de sus palabras (van Dijk, Ideologías, 1999, p. 122).

\section{¿Por qué nadie se mete con Álvaro Uribe?}

La Pulla, espacio de opinión del periódico El Espectador, intervino el 1 de marzo del 2018 con la pregunta ¿Por qué nadie se mete con Álvaro Uribe? A través del sarcasmo como estrategia discursiva, los periodistas María Paulina Baena y Juan Carlos Rincón, analizaron los pormenores históricos de la vida política de Álvaro Uribe Vélez para comprender su permanencia en el poder a pesar de los escándalos de corrupción y otros vicios políticos en los que se encuentra inmerso.

Baena y Rincón emprenden su análisis de opinión con los señalamientos que la prensa y varias investigaciones hacen sobre los nexos de Uribe con el paramilitarismo (fuerzas armadas al margen de la ley que sirven al Estado), narcotráfico, corrupción, violencia y obstrucción a la justicia, empleando en su video un léxico y entonación muy característicos del sarcasmo.

La configuración discursiva en La Pulla se reconoce en una narratividad interpretada por el Yo /Nosotros: Baena y Rincón, periodistas que representan una institución (El Espectador) opinan a través del sarcasmo con el objetivo de exponer los sofismas que continuamente predica Uribe para salir impune de señalamientos; Tú, Álvaro Uribe Vélez a quien se dirigen como el destinatario de las denuncias de Baena y Rincón; y el sofisma de la doctrina uribista como 'Él' de todo el argumento. En este 
sofisma se encuentra el espacio especular porque llama la atención: Uribe como paradoja del poder político.

Como resultado de esta configuración discursiva se revela la intencionalidad ideológica del discurso: Baena y Rincón, como voz de opinión de un periódico que históricamente responde a tendencias liberales, señalan una ética política reprochable en Uribe, pero a través de un lenguaje no metafórico sino de un juego dialéctico de inteligencia verbal que busca dar a entender un sentido contrario de lo que expresan sus oraciones llenas de ironía sarcástica (Laborda, 2002, p. 316).

Para comprender cómo este discurso de humor político, que se configura desde el sarcasmo, responde a la pregunta inicialmente planteada en este ensayo, se revisará la macroestructura, microestructura y superestructura del discurso en virtud de las postulaciones de Van Dikj.

Baena y Rincón configuran la macroestructura de su discurso en base a las proposiciones: Vamos a contarle la historia del hombre más poderoso del país / este hombre ha pasado por múltiples cargos políticos incluido el de presidente de Colombia / es Álvaro Uribe Vélez / fue señalado por otro político de tener nexos con el paramilitarismo / Uribe solicita al Congreso que le investigue a esa persona, quien sale indemne / en medio de esa investigación hallan que una tercera persona está hablando con testigos que podría incriminar a Uribe / Uribe está al tanto y registro de su conversación / ¿por qué se enteró? / nuevamente Uribe denuncia un complot / se le recuerda a Uribe que no hay complot sino malas amistades, ni persecución porque sus cercanos políticos son conocidos / Se califica a Uribe de conserje de la Patria / porque durante su gobernación concedió dudosas licencias para favorecer narcotraficantes, se incrementaron masacres en su departamento y se le relaciona con el paramilitarismo / y llega a la presidencia de la república en donde cometió más irregularidades además de corrupción / su círculo está inmerso, denunciado y enjuiciad por narcotráfico, paramilitarismo y corrupción / ¿por qué no sucede nada contra Uribe? / ¿Cuál es su verdadero poder? Si siempre se escuda en la 'persecución política'/ una dudosa persecución para un político que parece estar escondiéndose. 


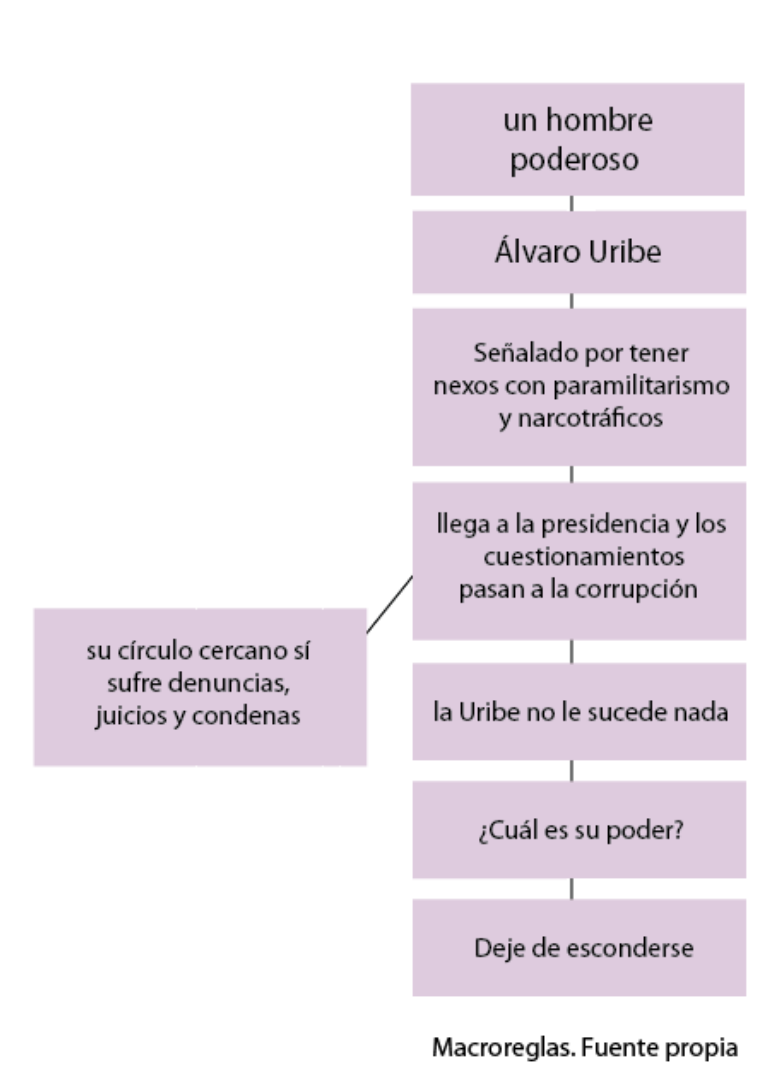

Bajo esta revisión, se definieron las siguientes macroproposiciones para conformar las macrorreglas del discurso: un hombre poderoso / Álvaro Uribe / Señalado por tener nexos con paramilitarismo y narcotráfico / llega a la presidencia y los cuestionamientos pasan a la corrupción / su círculo cercano sí sufre denuncias, juicios y condenas / a Uribe no le sucede nada / ¿Cuál es su poder? / Deje de esconderse.

Respecto a la semántica oracional, para definir la microestructura del discurso, Baena y Rincón emplean el sarcasmo para expresar sus ideas, en donde hay una evidente entonación y selección de calificativos de modo encubierto cuya interpretación no cae en ambigüedades (Martínez, 2016, pág.

207): “Queremos contarles la historia del hombre más poderoso del país, quien siempre se salva aunque todo arda a su alrededor" (Baena \& Rincón, 2018) = Exponemos la historia de un político que a pesar de denuncias en su contra no es enjuiciado / "Antioqueño de carriel y sombrero, de ojitos dulces como la miel, con una voz siseante de paisa bonachón....el héroe de esta patria" = Álvaro Uribe Vélez, un político que a pesar de las denuncias en su contra no logran enjuiciar / 'mano firme, corazón grande, falsos testigos" (Baena \& Rincón, 2018) = las dos primeras frases hacen referencia a su lema de campaña, pero una tercera frase le señala de acusar a quienes lo inculpan por paramilitarismo, y cómo Uribe se defiende (incriminando a sus adversario de crear falsos testigos).

Frente al análisis de Baena al revisar la investigación del Congreso de la República (al ser Uribe investigado por paramilitarismo), que encontró un tercer hombre que insistía en hablar con los testigos de Uribe y cuyas conversaciones fueron grabadas, señala: “¿Lo normal que uno dice cuando quiere que alguien de su versión libre!” (Baena \& Rincón, 2018) = sarcasmo para el eufemismo de esa situación, similar al escenario que se generó cuando este hombre llamó insistentemente a uno de los testigos antes del interrogatorio: "pues es que se le había quedado el almuerzo" (Baena \& Rincón, 2018), y ante el conocimiento de Uribe de estas investigaciones en su contra, Baena comenta “¿Quién carajos le contó?, ¡la ventaja de tener amigos bien conectados, ¿no?!” (Baena \& Rincón, 2018) = Uribe tiene conexiones políticas que le han permitido continuar su carrera política sorteando las denuncias en su contra.

Nuevamente Baena arremete contra Uribe cuando él denuncia persecuciones en su contra e intervención de su teléfono: "usted resultó llamando a los teléfonos que 
estaban interceptados, ¡ahí sí cagada!, 'cambiá' los números de tu agenda querido, 'relacionate' con gente buena” (Baena \& Rincón, 2018) = Baena en tono sarcástico y empleando palabras de acento paisa inculpa a un Uribe no inocente de sus acciones, asimismo y en relación al señalamiento de persecuciones respecto a políticos que alega no conocer, Baena comenta: "no es la primera vez que Uribe termina en un saco con gente intachable, ¡dime con quién andas y te diré quién eres!” (Baena \& Rincón, 2018) = Es demostrable que Uribe conoce a gran parte de los políticos con investigaciones por corrupción, con quienes ha tenido relaciones de trabajo.

Rincón, por su parte y en referencia a denuncias por narcotráfico contra Uribe, comenta: "Uribe que siempre cae parado, muy comprometido con su región, terminó de gobernador de Antioquia" (Baena \& Rincón, 2018) = A pesar de las denuncias que pesan en su contra siempre logra salir indemne de toda acusación, por otro lado, Rincón exhorta: “Uribe, por qué no en vez de seguir dando lora en el Senado te 'montás' una empresa de vigilancia, jte haces rico, hermano!" (Baena \& Rincón, 2018) = Ante los reparos de acusaciones, Uribe debería asumir que fundó y mantiene grupos de paramilitares.

Respecto a las acusaciones de corrupción, Baena continúa explicando que aún en medio de denuncias Uribe logra llegar a la presidencia: "llegó hasta la Presidencia de la República, y uno diría: ¡ya!, ese man se limpió de tanto amigo malo" = aun así en la presidencia, Uribe continúa con actos políticos reprochables, que esta vez llegan de la mano de la corrupción y en medio de un círculo cercano que se encuentra igualmente denunciado y enjuiciado. “¿Cuál es el poder real que tiene Uribe?” (Baena \& Rincón, 2018) = no comprendemos por qué un político que ha sido ampliamente señalado no esté cumpliendo condenas. Finalmente Baena y Rincón señalan: "Puede que sea inocente, puede que no, pero deje de jugar a las escondidas. 1, 2, 3 por Álvaro Uribe" (Baena \& Rincón, 2018), es decir, se cuestiona, a través del sarcasmo, que Uribe debería entregarse para colaborar con la justicia.

Las proposiciones textuales halladas definen los siguientes roles semánticos: Agente: los periodistas María Paulina Baena y Juan Carlos Rincón / Objeto: las evidencias de denuncias por narcotráfico, paramilitarismo y corrupción contra Uribe / Estímulo: la verdad / Instrumento: la denuncia a través de pruebas documentadas / Modo: el sarcasmo / Causa: encontrar la verdad en el poder de Uribe / Oponente - Álvaro Uribe Vélez. La presentación de ideas en el discurso de La Pulla se hace de forma clara en donde, a través del sarcasmo y oraciones yuxtapuestas, se plantea una crítica mordaz que encubre un propósito moralizante.

El sarcasmo transparenta la estrategia de enunciación de La Pulla a través del empleo de exhortaciones y apelaciones versificadas que, combinadas con expresiones fonéticas de Baena y Rincón, traslucen la intención de descalificar a quien critican, y mediante un acto 'pseudocortés' de dialéctica buscan deliberadamente un mayor impacto en su audiencia. Su paraverbalidad a través de pausas y silencios después de comentarios que incriminan y modos no verbales del habla (virar los ojos al aire) recalcan el tono sarcástico de su discurso. 
Por otro lado, la superestructura del discurso se define a partir de la gramática del relato que construyen Baena y Rincón, en donde se advierte la siguiente forma narrativa: el preludio del discurso sirve para presentar a Álvaro Uribe, un político señalado por sus relaciones con el paramilitarismo y el narcotráfico y quien a pesar de las pruebas nunca ha sido enjuiciado. En medio de ese escándalo logra llegar a la presidencia de la república en donde una vez más lo acompañan sus señalamientos, pero esta vez en medio de denuncias de corrupción. Baena y Rincón se preguntan por el verdadero poder de Uribe y su insistencia en escudarse en la persecución política como salida.

Asimismo, la estructura retórica de su discurso cumple principalmente un acto ilocutivo porque su intencionalidad a través del sarcasmo descalifica las acciones amorales de Uribe, y es en el sarcasmo que se consolida su estrategia retórica, pues busca transgredir la imagen del político (Cabedo, 2009, p. 21) y no pretende ser agradable en esa transgresión, que inclusive en ocasiones llega al insulto. Pero es su estilo sarcástico con el que pretende debilitar la estrategia dialéctica de Uribe.

Finalmente, en el video de La Pulla resalta una primera imagen que antecede la estrategia retórica de su discurso: después de introducir el objeto de su investigación, Baena y Rincón se llevan las manos al pecho en un gesto de aparente respeto, para mencionar que su personaje fue presidente de la república, solo para continuar con la mención de todas las atrocidades que se le adjudican, un gesto que después comprendemos como un reproche desde el sarcasmo.

Baena y Rincón validan su discurso en YouTube, un canal con más de 730 mil visualizaciones, con más de 400 mil suscripciones al canal y cerca de 5 mil comentarios al video de opinión de El Espectador, La Pulla, un nombre que además busca validar su estilo discursivo en el sarcasmo, puesto que pullar implica enardecer con expresiones agudas.

\section{Discusión}

En ambos videos se apuesta por un discurso persuasivo, como llamado de atención, a través de una preocupación implícita: la impunidad que permite continuar en la política a Álvaro Uribe. Es él el sujeto blanco de las críticas, bien desde la sátira o desde el sarcasmo, quien seduce al discurso transgresor.

En el discurso de Samper, Baena y Rincón se busca emular las palabras de van Dijk cuando estos se preguntan por la clase de creencias que están involucradas en la ideología, pero se lo preguntan a través del ejercicio retórico de la sátira y del sarcasmo como estrategia discursiva, porque con su estrategia buscan llamar la atención hacia esa otra ideología que moralmente es inaceptable.

Ambos programas hablan desde una moral universal (entiéndase esta como la ideología a la que se hacen partícipes) solo para pedir la atención sobre esa moral que está siendo atacada por un sujeto amoral (chismoso, asesino, corrupto, en palabras de 
Baena y Rincón). Con su propuesta transgresora, estratégicamente respaldada en un marco jurídico internacional que la avala, se transparenta el juego discursivo del otro.

Álvaro Uribe queda expuesto en este juicio basado en valores y normas socialmente compartidas que indican cómo comportarse dentro de esta ideología, que enmarcada dentro del análisis de estudio, es política y social: es socialmente reprochable la corrupción, el asesinato y el amparo de criminales, normas que son igualmente aceptadas para el desenvolvimiento político, y por lo tanto para quien funge como representante en este juego social que implica la política.

Estas normas de comportamiento se evidencian en el juicio valorativo que comparten los periodistas sujetos de esta investigación. Ellos señalan quien incumple la norma, y lo hacen en pleno ejercicio de sus derechos, por una parte, como miembros de esa gran ideología, y por otra, como especialistas de la palabra a través del ejercicio del periodismo de opinión. Es con la opinión que su trabajo establece el operativo de control para preservar la democracia. Ellos controlan el discurso para doblegar al poder.

Sus valores son por lo tanto: la no impunidad, el cumplimiento con la justicia, la no obstrucción de las investigaciones por delitos, el rechazo al asesinato y el rechazo al narcotráfico, contravalores que invisten a Uribe en el video de Samper, Baena y Rincón.

A través de la estructura del discurso enmarcada en el humor político, se emplean recursos metafóricos que buscan el acto ilocutivo y perlocutivo como efecto de sus palabras. Samper emplea la hipérbole dentro de una sintaxis de construcción comparativa: él sobre un caballo pequeño de madera, bebiendo café, hablando con acento paisa mientras pronuncia una frase congruente pero carente de toda lógica, emula a Uribe hablando ante los congresistas del país. Su estrategia retórica distorsiona la realidad pero pone en evidencia una corrupción real (Llera, 1998-1999, p. 9).

Baena y Rincón, a través del sarcasmo, juegan con expresiones exhortativas que no requieren interpretación, porque son directas y en su retórica además emplean expresiones fonéticas cuyos modos paraverbales y no verbales denotan su inclinación sarcástica: ambos se llevan las manos al pecho en muestra de respeto aparente por un político que van a incriminar.

Se asiste entonces a un discurso que explicita las acciones políticas de Álvaro Uribe a través del señalamiento investigativo histórico que realizan los periodistas, pero implícitamente buscan denostar la imagen de un político que ha cometido actos reprochables en virtud de las representaciones mentales que se comparte en una sociedad democrática, que exige este tipo de cuestionamientos para seguir funcionando.

Sin embargo, ese señalamiento no está exento de polémica, porque como existen representaciones mentales compartidas por el grupo (sociedad democrática) también existe quienes no las comparten (Samper asiste a una marcha de la que es expulsado por coidearios de Uribe, que se acogen a su ideología) pero es precisamente esta polémica la que genera el debate para el control democrático. 
Una polémica similar se traslada desde el espacio físico de la marcha al espacio en línea de las redes sociales. El enlace de Youtube en donde se aloja el video, cuenta con 7296 intervenciones de usuarios que opinaron a favor o en contra de las acciones. Un porcentaje de usuarios consideró las implicaciones positivas y negativas de la marcha mientras que otro porcentaje de usuarios se inclinó por calificar las acciones de Daniel y Vladdo respecto a su participación en la misma.

\section{Conclusión}

Bajo este análisis planteado se da respuesta a la premisa inicialmente planteada: ¿es el humor político un discurso que fomenta el control democrático de la gestión pública a través de la discusión y opinión?

A través del humor político como estrategia discursiva se puede romper con discursos que vulneran la ideología que comparte una sociedad, para este caso, una sociedad democrática, no solo porque señala a quienes buscan romper con las normas impuestas, también porque al disgregar el pensamiento en unidades comprensibles (a través del humor) se genera un nuevo pensamiento.

Con los planteamientos que explicita el humor se plantea la discusión, porque el romper con posiciones que atentan contra las representaciones mentales de la mayoría, le contrarresta y por añadidura le quita valor y poder. Por lo tanto, se asiste con el humor al contrapeso del poder, que en definitiva, es lo que necesita la democracia para existir.

Este contrapeso al poder, como su función social emplea el lenguaje, sus formas del habla y estrategias discursivas (humor), para contrarrestar otro lenguaje, el que atenta contra las normas. Pero es en virtud de su función social que se vale de la estrategia discursiva del humor (sátira y sarcasmo) para descalificar y buscar la forma de generar debate.

Por lo tanto se asiste al control democrático de la gestión pública a través del ejercicio reflexivo y de debate que genera el humor político como discurso, mismo que se evidencia no solo en las acciones de las personas que asisten a la marcha, se evidencia también en las posteriores intervenciones en la red social Youtube para opinar a favor o contra a partir de un discurso satírico que permite el debate democrático. 


\section{Bibliografía}

Acosta, G., \& Sánchez, J. (2004). Construcción de identidad y función política en el discurso del Director de Comunicaciones. Medellín: Universidad de Medellín.

Baena, M. P., \& Rincón, J. C. (marzo de 2018). ¿Por qué nadie se mete con Álvaro Uribe? (YouTube) La Pulla (canal de opinión de El Espectador). Recuperado el marzo de 2018, de https://www.youtube.com/watch?v=B_D0q1joElI

Cabedo, A. N. (2009). Análisis y revisión del sarcasmo y la lítote: propuesta desde la Teoría de la Relevancia. Boletín de Filología, Tomo XLIV. Número 2, 11 - 38.

CIDH. (2010). Marco jurídico Interamericano sobre el derecho a la libertad de expresión. Relatoria Especial para la Libertad de Expresión. Obtenido de www.oas.org/es/cidh/expresion/docs/publicaciones/MARCO\%20JURIDICO $\% 2$ OINTERAMERICANO\%20DEL\%20DERECHO\%20A\%20LA\%20LIBERTAD \%20DE\%20EXPRESION\%20ESP\%20FINAL\%20portada.doc.pdf

González, J., \& Ortiz, A. (1999). El espot publicitario. La metamorfosis del deseo. Madrid: Ediciones Cátedra S.A.

Heredia, R. (septiembre de 2013). Humor y discurso: una propuesta para el análisis de la protesta en YouTube. (U. d. Valle, Ed.) Lenguaje. Scielo colombia (Scientific electronic library online)(44), 83-109. Recuperado el 14 de marzo de 2018, de Humor y discurso: una propuesta para el análisis de la protesta en YouTube: www.scielo.org.co/pdf/leng/v44n1/v44n1a05.pdf

Laborda, X. (2002). Ironía, sarcasmo y cortesía en el agradecimiento político. Oralia, 313-322.

Lakoff, G. (1991). La Metáfora en Política. Carta abierta a Internet. Recuperado el 10 de febrero de 2018, de Intef Instituto Nacional de Tecnologías Educativas y de Formación del Profesorado.: http://serbal.pntic.mec.es/ cmunoz11/guerra.pdf

Lakoff, G., \& Johnson, M. (2004). Metáforas de la vida cotidiana. (2da. Edición ed.). Cátedra, Colección Teorema.

Llera, J. A. (1998-1999). Prolegómenos para una teoría de la sátira. Tropelías, 281-293.

Martínez, E. (2016). De la ironía al sarcasmo: una aproximación al discurso parlamentario españo. Texto en proceso TEP 2, 194-216. Obtenido de Texto en proceso TEP.

Samper, D. (12 de Octubre de 2017). Fuimos a marchar contra la corrupción pero no les gustó (Ft Vladdo). Hola Soy Danny (YouTube). Recuperado el marzo de 2018, de https://www.youtube.com/watch?v=omywYajwKB0\&t=290s

van Dijk, T. (1999). Ideologías. Barcelona: Gedisa, S.A.

van Dijk, T. (2000). El discurso como interacción social. Barcelona: Gedisa S.A. 
van Dijk, T. (junio de 2005). Ideología y análisis del discurso. Recuperado el marzo de 2018, de Utopìa y Praxis Latinoamericana [online]. 2005, vol.10, n.29. pp. 9-36: www.scielo.org.ve/scielo.php?script=sci_arttext\&pid=S1315-

$52162005000200002 \& \operatorname{lng}=$ es\&nrm=iso 